\title{
Heating Performance Study on a Passive Solar Heater
}

\author{
Muhammad Y. Naz ${ }^{1 *}$, Shaharin A. Sulaiman ${ }^{2}$, Tahir Mahmood ${ }^{l}$, Muhammad I. Hussain ${ }^{l}$, \\ Abdul Ghaffar ${ }^{l}$, Yasir Jamil ${ }^{1}$, Muddasser Inayat ${ }^{2}$ \\ ${ }^{1}$ Department of Physics, University of Agriculture, 38040 Faisalabad, Pakistan. \\ ${ }^{2}$ Department of Mechanical Engineering, Universiti Teknologi Petronas, 32610 Bandar Seri Iskandar, \\ Perak, Malaysia
}

\begin{abstract}
A passive thermosyphon heating system was designed, fabricated and tested for its thermal performance in semi-arid and four-season climate of Pakistan. The heating system design was based on a two-stage storage and natural thermosyphon circulation of the water. The objective of the study was to enhance the heating performance of the thermosyphon systems by using a semicircular steel pot collector, water carrying copper coil cover, two step water storage, and side mirror reflectors. The experiments were conducted during April to July 2014 when ambient temperature was reported to vary between $32^{\circ} \mathrm{C}$ and $44^{\circ} \mathrm{C}$. In continuous flow mode operation, the hot water temperature remained between $46^{\circ} \mathrm{C}$ and $78^{\circ} \mathrm{C}$. Since water temperature in the range of $45^{\circ} \mathrm{C}$ to $50^{\circ} \mathrm{C}$ is considered suitable for the domestic use, the presented design can easily reach the temperatures even higher than those acceptable for the domestic use.
\end{abstract}

\section{Introduction}

Pakistan is one of those countries, which have abundant sunshine during the most days of a year. With 320 days of annual sunshine generally there are four seasons in the district Faisalabad of Pakistan. During this period, climate vary from very low to high temperatures. The residents of Faisalabad use flat plates (black coated solar collectors) to maximize the absorption of radiant energy [1-3]. However, such models have failed in least sunny days of winter season. The low performance of such collector models. So geometrical improvement are referred.

Based on construction, the solar water heaters are classified into active and passive systems. In active systems, there is a need of electric pump, valves and controllers to circulate the water, whereas the passive systems do not require external pumping for water circulation. Normally, direct systems are complicated, expensive, sensitive to freezing conditions and can only heat the water to moderate temperatures in the range of 50 to $60^{\circ} \mathrm{C}$ [4]. Nevertheless, few design alterations are possible to overcome the freezing issues. In passive solar heating systems, the heat transfer takes place by means of convection. Circulation of the water takes place through a natural process rather than forced circulation. Such systems are cheap, easy 
to handle and flexible, when compared to active systems.

Thermosyphon systems are generally more reliable type of passive heating systems due to their easy installation, low maintenance cost and long life [5]. The presented work is an example of thermosyphon heating system based on two stage storage and natural thermosyphon circulation of water. A passive thermosyphon heating system was designed and tested for its thermal performance. Effect of different methods of solar heat transformation were also investigated. Although some literature already exsists on such type of water heaters, the objective was to enhance the heating efficiency of thermosyphon system. For this purpose, a circular pot collector, double storage tanks, and side mirror reflectors were used to maxamine the heat transfer.

\section{Materials and Methods}

A passive thermosyphon heating system was designed and fabricated with locally available materials but not of specialty items. The detailed specifications of the system design are given in Table 1. A circular pot was housed in an air tight box and covered with spiral semi-circular copper pipes connected across the water tanks in such a way to form a thermosyphon system, as shown in Fig. 1.

Mirror reflectors were used at the back side of upper and lower storage tanks inside the box to focus the sun rays on water tanks. A steel reflector was used at the base of the box to reflect the sun rays. A circular pot of steel having diameter of $30 \mathrm{~cm}$ was used as a heat absorber. The top rough surface of the pot was painted black to maximize the absorption of radiations, while sides of the pot were polished with silver buffer for high reflection of the radiations. The copper pipe and storage unit were also painted black to maximize the heat absorption.

Table 1. Materials used in fabrication of a passive thermosyphon heating system.

\begin{tabular}{|l|l|l|l|l|l|}
\hline \multirow{2}{*}{ Sr. Item } & \multicolumn{2}{l}{ Quantity } & \multicolumn{3}{l}{ Specifications } \\
\cline { 4 - 6 } & & & Length & Width & Thickness \\
\hline 1 & Steel sheet & 1 & $150 \mathrm{~cm}$ & $120 \mathrm{~cm}$ & 26 gauge \\
\hline 2 & Glass sheet & 1 & $150 \mathrm{~cm}$ & $120 \mathrm{~cm}$ & $0.5 \mathrm{~cm}$ \\
\hline 3 & Copper pipe & 5 & $150 \mathrm{~cm}$ & $1.27 \mathrm{~cm}$ dia. & - \\
\hline 4 & $\begin{array}{l}\text { Hard board } \\
\text { sheet }\end{array}$ & 2 & $150 \mathrm{~cm}$ & $120 \mathrm{~cm}$ & - \\
\hline 5 & Foam sheet & 1 & $150 \mathrm{~cm}$ & $120 \mathrm{~cm}$ & $2.5 \mathrm{~cm}$ \\
\hline 6 & Circular iron pot & 1 & - & $\begin{array}{l}\text { Dia. }=30 \\
\mathrm{~cm}\end{array}$ & $0.3 \mathrm{~cm}$ \\
\hline 7 & Rubber pipe & $1.25 \mathrm{~cm}$ & $300 \mathrm{~cm}$ & - & $\begin{array}{l}\text { Dia. }=1.27 \\
\mathrm{~cm}\end{array}$ \\
\hline 8 & Mirror reflector & 4 & & & \\
\hline
\end{tabular}




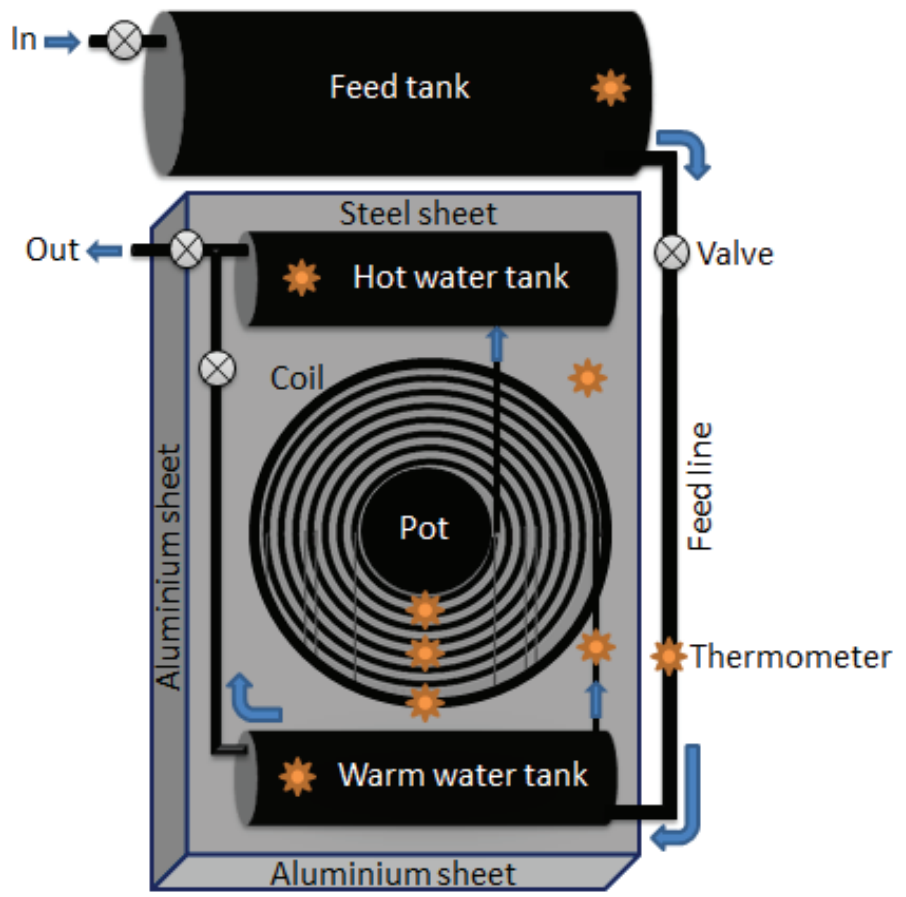

Fig. 1. Detailed drawing of the passive thermosyphon system with two-step water storage.

\section{Results and Discussion}

In this research work, a new configuration of passive solar water heater was tested with a group of thermosyphon effects, also known as gravity heat pipes. Totally solar based direct radiation energy was used to heat-up the water for domestic use. The water in the lower internal tank was heated through thermosyphon phenomenon. Being less dense, the hot water in the spiral copper pipe-line moved upward to the upper storage tank inside the box. The concerned parameters of the process were studied in the months of April, May, June and July of 2014, under different weather conditions of Faisalabad. The performance of the heater was monitored every day from 8:00 am to 6:00 pm.

The presented design was an example of thermosyphon heating system based on twostage storage and natural thermosyphon circulation of water. The water pressure of the external tank at its full storage capacity was calculated as:

$$
\mathrm{P}_{\mathrm{T}}=\rho g \mathrm{WH}_{\mathrm{T}}
$$

where ' $\mathrm{P}_{\mathrm{T}}$ ' is the pressure of cold water storage tank, ' $\mathrm{g}$ ' is the gravitational acceleration $\left(\mathrm{m} / \mathrm{s}^{2}\right)$, ' $\mathrm{\rho}$ ' is the density of the cold water $\left(\mathrm{kg} / \mathrm{m}^{3}\right)$, ' $\mathrm{W}$ ' is the weight and ' $\mathrm{H}_{\mathrm{T}}$ ' is the height of the water tank from ground. The equation (1) reveals that the water pressure increases linearly with height of the water tank. This increase in pressure inside the tank causes an increase in the flowrate of the water through flat-plate collector. It predicts an improvement in the system performance on account of faster heat transfer from collector to the water, thereby minimizing the convection and other losses from the collector.

The coefficient of cubic expansion of water was determined at different temperatures. The cylindrical water tanks, made-up of mild steel, were subjected to internal pressure of water at different temperatures. It was observed that the coefficient of cubic expansion 
linearly increases with water temperature. The pressure is generally considered as uniformly distributed over the internal surface of the tank. If the wall thickness is equal to or less than $1 / 20$ of the internal diameter, the vessel is said to be thin-walled; otherwise, it is considered as a thick-walled vessel. In this work, the water tanks were made of mild steel with yield strength of $176 \mathrm{MPa}$. The height of the cold-water tank from the ground was $0.9 \mathrm{~m}$, height of the hot water tank was $0.2 \mathrm{~m}$ and the wall thickness of the tank was $0.5 \mathrm{~mm}$. This information reveals that for a thin-walled cylinder, the wall thickness is related to the diameter via the following inequality ' $t \leq \frac{1}{20} \mathrm{D}_{\mathrm{T}}$ '. This relation holds for both cold water tank and hot water tank. Therefore a bursting stress also known as tangential or circumferential stress will be set-up on the wall of the cylindrical tank due to the water pressure. The tangential stress for cold water tank can be elaborated from the relation:

$$
\begin{gathered}
2 \sigma_{\mathrm{t}} \mathrm{H}_{\mathrm{T}} \mathrm{t}-\mathrm{P}_{\mathrm{T}} \mathrm{D}_{\mathrm{T}} \mathrm{H}_{\mathrm{T}} \\
\sigma_{\mathrm{t}}=\mathrm{P}_{\mathrm{T}} \mathrm{D}_{\mathrm{T}} / 2 \mathrm{t}
\end{gathered}
$$

where ' $\sigma_{\mathrm{t}}$ ' the tangential stress for cold water tank, ' $\mathrm{H}_{\mathrm{T}}$ ' is the height of the water tank from ground, ' $\mathrm{t}$ ' is the thickness and ' $\mathrm{D}_{\mathrm{T}}$ ' is the diameter. Same relation is applicable for tangential stress in hot water tank $\left(\sigma_{\mathrm{t}}{ }^{\prime}=\mathrm{P}_{\mathrm{T}}{ }^{\prime} \mathrm{D}_{\mathrm{T}}{ }^{\prime} / 2 \mathrm{t}\right)$, where $\mathrm{P}_{\mathrm{T}}{ }^{\prime}$ is internal pressure of hot water tank and $\mathrm{P}_{\mathrm{T}}$ is internal pressure of cold water tank. In the given heater design, $\mathrm{P}_{\mathrm{T}}$, $\mathrm{P}_{\mathrm{T}}{ }^{\prime}, \sigma_{\mathrm{t}}$ and $\sigma_{\mathrm{t}}{ }^{\prime}$ were calculated about $8820 \mathrm{~N} / \mathrm{m}^{2}, 1910.6 \mathrm{~N} / \mathrm{m}^{2}, 7.9 \mathrm{MPa}$ and 3.8 MPa, respectively. Since the water tanks were closed, the longitudinal stress $\sigma_{1}$ was also taken into account due to the water pressure on ends of the tanks. Assuming the uniform distribution of the stress, $\sigma_{1}$ was calculated about $9 \mathrm{MPa}$.

The efficiency on $1500 \mathrm{ml}$ water of the solar water heater was checked, from 8:00 am to 6:00 pm after every 30 minutes during a day. In discontinu flow mode operation, the total water taken out during these ten hours was 30 litters. The cold-water temperature remained in the range of 18 to $28^{\circ} \mathrm{C}$ for the stated time period. In Fig. 2, the maximum water temperature remained between $48^{\circ} \mathrm{C}$ to $88^{\circ} \mathrm{C}$ when ambient temperature was in the range of 32 to $44^{\circ} \mathrm{C}[8]$.

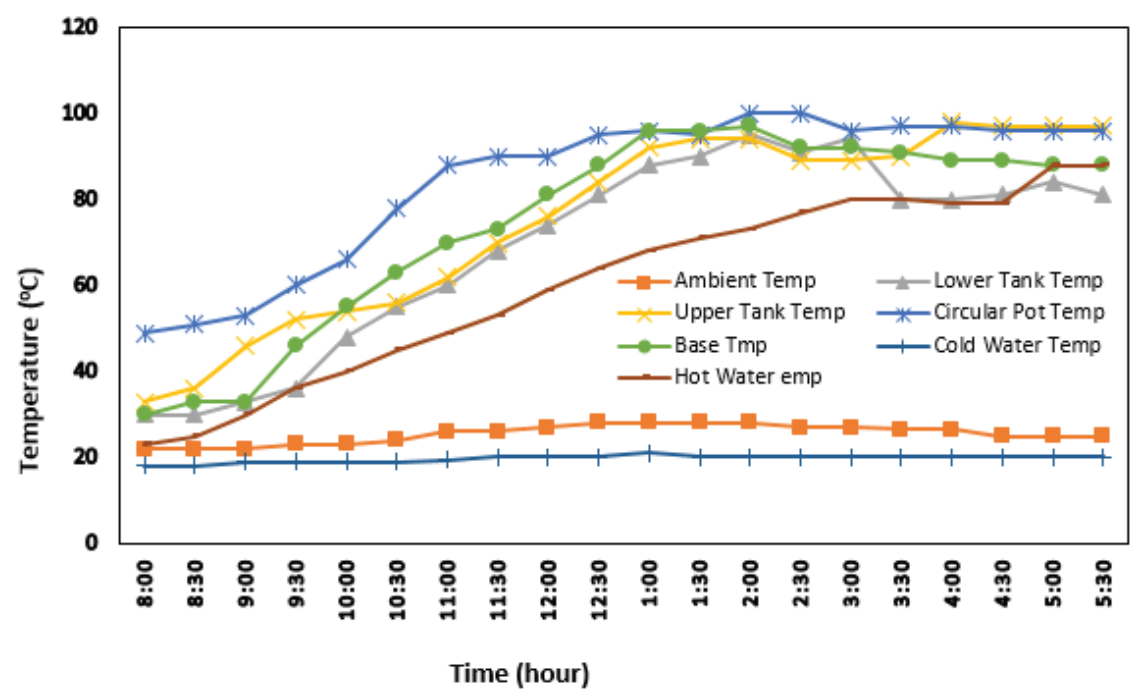

Fig. 2. Change in water temperature over time at different points on the solar water heater during intermittent water flow. 
The water temperature in continuous flow mode operation of thermosyphon system was also measured, as reported in Fig. 3. The water discharge rate was fixed to 10 liters per hours. The maximum temperature of $78^{\circ} \mathrm{C}$ was achieved when ambient temperature was in the range of $36^{\circ} \mathrm{C}$ to $43^{\circ} \mathrm{C}$. The high heating performance of the heater was attributed to the roughness and darkness of the pot surface. The copper coil, covering the pot, also contributed to the maximum energy conversion during the heating process $[9,10]$. The reflected part of the radiative energy was trapped in the copper carrying the water. The airtight box with glass cover also minimized the heat and radiative losses from the wooden box.

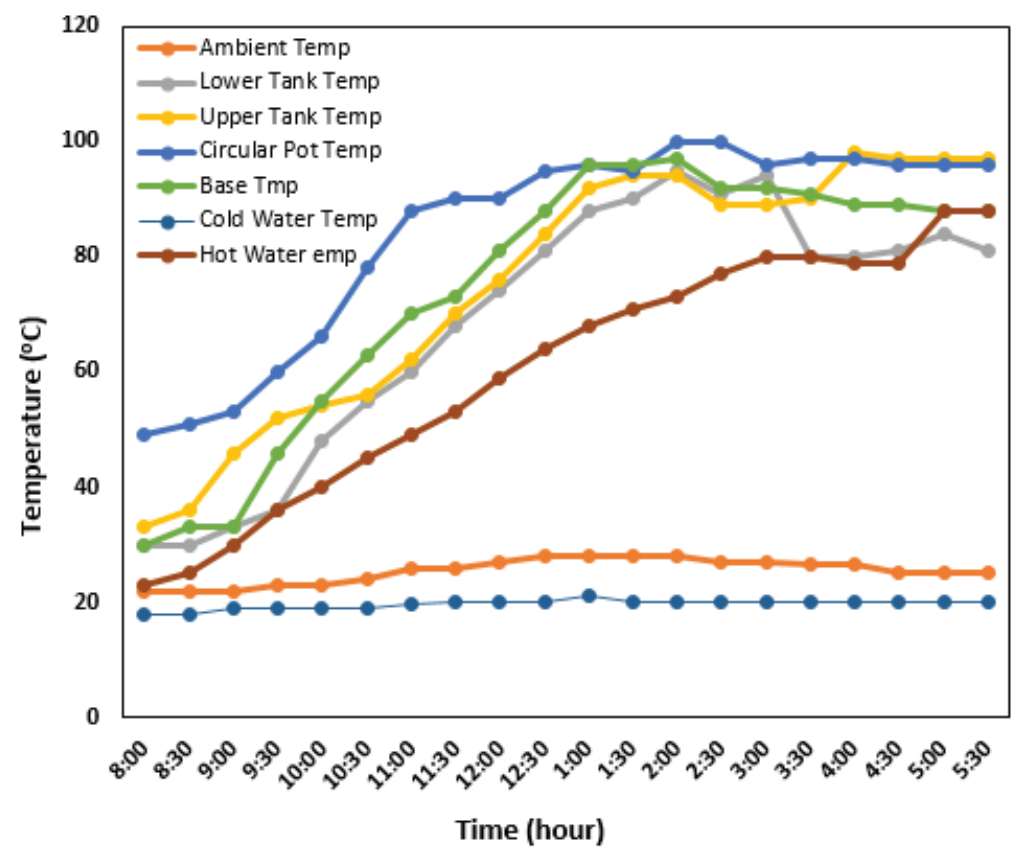

Fig. 3. Change in temperature over time at different points on the solar water heater during continuous flow.

The operating characteristics of the thermosyphon solar water heaters can also have significant impact on the efficiency of the system, because the performance of the system was based on the flowrate from the collector, absorber plate temperature and temperature rise of the water from inlet to outlet [9]. Ho and Chen [11] revealed that the sheet and tube based solar water heating is a convenient way of heating the water for domestic use. Considerable improvement in the collector performance was reported by Ho and Chen [11] by employing a water recycling operation. Similar findings are reported in the presented work.

\section{Conclusion}

This work reports the design, fabrication and performance study of a passive thermosyphon type solar water heater. The maximum water temperature, sustained by the system in intermittent flow mode operation, remained between $48^{\circ} \mathrm{C}$ to $88^{\circ} \mathrm{C}$. In continuous flow mode operation, the hot water temperature reached to $46^{\circ} \mathrm{C}$ to $78^{\circ} \mathrm{C}$. The water stored in the temperature range of $45^{\circ} \mathrm{C}$ to $50^{\circ} \mathrm{C}$ is considered suitable for domestic use. However, this study revealed that the presented design can easily reach the temperatures even higher than those acceptable for domestic use of water. The high performance of the presented heater design was attributed to the rough and dark surface of the pot and semicircular coil covering. 
The copper coil also ensured the maximum energy conversion in the heating process. Most of the radiative energy incident on the pot was absorbed by its painted black surface. The reflected part of the radiative energy was trapped in the copper carrying the water. The airtight box with glass cover also helped minimizing the heat and radiative losses.

\section{References}

1. A. Hasan, ECM 38(9), 847-54 (1997)

2. R. Tang, Y. Cheng, M. Wu, Z. Li, Y. Yu, ECM 51, 2548-2556 (2010)

3. A. Sakhrieh, A. A. L. Ghandoor, ECM 65, 715-720 (2013)

4. R. Kumar, M. A. Rosen, ATE 30, 1764 (2010)

5. S. A. Kalogirou, STCAPECS 30, 231 (2004)

6. H. Zhai, Y. J. Dai, J. Y. Wu, R. Z. Wang, L. Y. Zhang, ECM 51, 48-55 (2010)

7. O. Tiago, C. M. Joao. EP 30, 1344-53 (2012)

8. B. J. Huang, C. T. Hsieh,SE 35, 31-43 (1985)

9. S. Jaisankar, T. K. Radhakrishnan, K. N. Sheeba. SE 83, 19431952 (2009)

10. S. Jaisankar, T. K. Radhakrishnan, K. N. Sheeba, S. Suresh, ECM 50, 2638-2649 (2009)

11. C. D. Ho, T. C. Chen, RE 33, 655-664 (2008) 